\title{
Defibrillation threshold of internal cardioversion prior to ablation predicts atrial fibrillation recurrence
}

\author{
kohei sawasaki ${ }^{1}$, Yasuya Inden ${ }^{2}$, natsuko hosoya ${ }^{1}$, masahiro muto $^{1}$, and Toyoaki Murohara ${ }^{2}$ \\ ${ }^{1}$ Hamamatsu Medical Center \\ ${ }^{2}$ Nagoya University Graduate School of Medicine
}

November 26, 2020

\begin{abstract}
Background: Many studies have reported the predictors of atrial fibrillation (AF) recurrence after persistent AF (peAF) ablation. However, the correlation between the atrial defibrillation threshold (DFT) for internal cardioversion (IC) and AF recurrence rate is little-studied. We investigated the relationship between DFT prior to catheter ablation for peAF and the AF recurrence. Method and Results: From June 2016 to May 2019, we enrolled 82 consecutive patients (mean age $65.0 \pm 12.4$ years), including 45 patients with peAF and 37 with long-standing peAF, at Hamamatsu medical center. In order to assess the DFT, we performed IC with gradually increasing energy prior to radiofrequency application. Forty-nine and 33 patients showed DFT values less than or equal to $10 \mathrm{~J}$ (group A) and greater than $10 \mathrm{~J}$ or unsuccessful defibrillation (group B), respectively. During the mean follow-up duration of $20.5 \pm 13.1$ months, patients in group B showed significantly higher AF recurrence rates than those in group A after the ablation procedure $(\mathrm{P}=0.017)$. Multivariate analysis revealed that the DFT was the only predictive factor for $\mathrm{AF}$ recurrence $(\mathrm{OR}=1.07 ; 95 \% \mathrm{CI}: 1.00-1.13, \mathrm{P}=0.047)$. Conclusions: The DFT for IC was one of the strongest prognostic factors in the peAF ablation procedure.
\end{abstract}

\section{Hosted file}

Defibrillation threshold of internal cardioversion prior to ablation predicts atrial fibrillation recur available at https://authorea.com/users/379042/articles/495407-defibrillation-threshold-ofinternal-cardioversion-prior-to-ablation-predicts-atrial-fibrillation-recurrence

\section{Hosted file}

Defibrillation threshold of internal cardioversion prior to ablation predicts atrial fibrillation recur available at https://authorea.com/users/379042/articles/495407-defibrillation-threshold-ofinternal-cardioversion-prior-to-ablation-predicts-atrial-fibrillation-recurrence

\section{Hosted file}

Defibrillation threshold of internal cardioversion prior to ablation predicts atrial fibrillation recur available at https://authorea.com/users/379042/articles/495407-defibrillation-threshold-ofinternal-cardioversion-prior-to-ablation-predicts-atrial-fibrillation-recurrence

\section{Hosted file}

Defibrillation threshold of internal cardioversion prior to ablation predicts atrial fibrillation recur available at https://authorea.com/users/379042/articles/495407-defibrillation-threshold-ofinternal-cardioversion-prior-to-ablation-predicts-atrial-fibrillation-recurrence

\section{Hosted file}


Defibrillation threshold of internal cardioversion prior to ablation predicts atrial fibrillation recur available at https://authorea.com/users/379042/articles/495407-defibrillation-threshold-ofinternal-cardioversion-prior-to-ablation-predicts-atrial-fibrillation-recurrence 